\title{
Conceitos de Liderança e Competências Necessárias para ser um Bom Líder
}

\author{
MACHADO, Michel Pedrosa
}

MACHADO, Michel Pedrosa. Conceitos de Liderança e Competências Necessárias para ser um Bom Líder. Revista Científica Multidisciplinar Núcleo do Conhecimento. Ano 03, Ed. 03, Vol. 03, pp. 245-267, Março de 2018. ISSN: 2448-0959

\section{RESUMO}

A liderança é um assunto muito discutido na atualidade, enfatizando a importância do gestor nos resultados obtidos por uma equipe. Em um ambiente empresarial encontramos várias metodologias para a criação e implementação de projetos, gestão de equipes, sistemas como o Just-in-time, dentre outros, sendo que todos dependem de uma boa colaboração dos profissionais envolvidos para seu sucesso, o que só é possível com a ajuda de um líder eficaz. Este trabalho tem como objetivo descrever os tipos de líderes e as características comuns a eles, além de explicitar obrigações importantes ao bom funcionamento do grupo de trabalho, como o treinamento, feedback e a motivação. A metodologia utilizada foi a realização de uma pesquisa bibliográfica, tendo como principais referências James Hunter, Stephen Covey, Daniel Goleman e Jill Geisler.

Palavras-Chave: Liderança, Gestão de Equipes, Motivação, Treinamento.

\section{INTRODUÇÃO}

Este artigo tem como finalidade expor as principais características de um bom líder, de acordo com a literatura disponível, e também como desenvolver as principais competências para obter sucesso em seu trabalho, tais como o treinamento dos liderados, como motivar e desenvolver um bom relacionamento com os mesmos para que haja um ambiente saudável para o desempenho das funções.

O mundo como o conhecemos nem sempre foi assim, com informações sendo transmitidas em tempo real, smartphones, computadores, aeronaves que conseguem quebrar a barreira do som, dentre outros. Estas realidades são resultado de um processo evolutivo. 
Na pré-história, o homem morava em cavernas esculpidas nas montanhas pelos intemperes e os utensílios utilizados pelo mesmo eram pedaços de madeira pouco trabalhados ou pedras. Passaram-se milhares de anos até que surgisse o primeiro tear e, posteriormente, que ocorresse a revolução industrial, onde uma máquina movida a vapor poderia reproduzir o esforço repetitivo e sem necessidade de raciocínio do ser humano, conseguindo produzir mais em menos tempo, sem reclamações ou necessidade de pausas para se alimentar, tomar água ou ir ao banheiro.

Essas máquinas são um marco muito importante na evolução humana, pois, a partir destas, a criação e o progresso das tecnologias passou a acontecer num ritmo intenso. Apenas para fins de comparação, o homem, com o comportamento moderno, está presente no Planeta Terra há mais de 50 mil anos, sendo que, apenas em meados de 1760 ocorreu o início da Revolução industrial, ou seja, há menos de 3 séculos em que a produção em massa tornou-se uma realidade.

Apesar do início ter ocorrido no século XVIII, sua conclusão ocorreu no século seguinte, quase 100 anos após seu início. Hoje, século XXI, apenas dois séculos após o fim deste marco, os cientistas trabalham no aprimoramento da Inteligência Artificial, algo inimaginável a 200 anos atrás.

A tecnologia está realizando, a cada dia mais, trabalhos mecânicos, os quais demandam pouca capacidade de raciocínio, tais como registrar e comparar informações com um padrão preestabelecido, atividade comum no controle de processos industriais. Softwares permitem a criação de desenhos e a simulação do funcionamento de um componente mecânico em 3D, como é o caso do SolidWorks e do AutoCAD.

Estas inovações promovem uma migração da mão-de-obra de esforço físico para as de exigências intelectuais, onde o intelecto humano desempenha um papel primordial para os resultados econômicos de um processo.

As novas descobertas no mundo tecnológico promovem um aumento da especialização do profissional, e a multidisciplinaridade dentro de uma empresa promove a formação de equipes, também, multidisciplinares. Sendo assim, é comum observar engenheiros mecânicos, eletricistas, civis, ambientais, profissionais de programação de softwares, dentre outros, trabalhando em conjunto.

A Liderança entra em ação neste ponto, sendo o líder o responsável por fazer com que a equipe trabalhe de maneira harmônica, extraindo-se o melhor de cada profissional, para que as metas estabelecidas sejam atingidas de forma satisfatória.

A grande dificuldade da administração das equipes se encontra no fato de, além das especialidades distintas, existem também diferentes culturas, valores, objetivos de vida, gerações, situação financeira e etc.

O choque entre gerações é um dos grandes desafios da liderança atualmente. Num passado recente, devido aos meios de comunicação não serem abrangentes como hoje, o conhecimento não era tão disponível e acessível, sendo difundido apenas através de livros físicos e por especialistas.

Somado a isso, o fato do trabalho ser mecânico e repetitivo, o trabalhador era, como afirma Mario Sergio Cortella (2016), "robotizado" sendo alheio a função desempenhada, onde apenas obedecia a ordens. Devido à esta realidade, os líderes de gerações anteriores apenas precisavam dizer aos seus subordinados 
“o que fazer" e "como" fazê-lo, o mesmo não questionava e nem retrucava as ordens, apenas as repetia.

Com o advento da globalização das informações, dos conhecimentos e da tecnologia, a mão-de-obra pensante está em ascensão. Esta nova geração de trabalhadores não se motiva apenas com o salário digno, condições adequadas de trabalho ou bonificações por metas atingidas, sendo estas, atualmente, necessidades básicas para se desempenhar um bom trabalho.

Segundo Mario Sergio Cortella (2016), o trabalhador contemporâneo necessita ver sentido no que está realizando, ou seja, seus valores pessoais necessitam estar em consonância com o trabalho que está desempenhando, para que esteja realmente motivado a realizá-lo.

Esta diferença entre as gerações está muito relacionada às necessidades das mesmas. As gerações passadas tinham como prioridade a sobrevivência própria e de seus familiares. Atualmente, com a melhoria da distribuição de renda e com as famílias reduzindo o número de integrantes, tornou-se menos complicado mantê-la. Sendo assim, os trabalhadores do século XXI demandam outro tipo de liderança, que não apenas diga o que fazer e pague seu salário, mas que forneça os meios para que o trabalhador consiga se sentir bem com a função que está desempenhando.

\section{LIDERANÇA}

Para uma melhor abordagem sobre o tema, torna-se necessário expor suas definições, as de chefe e de gerente, sendo importante destacar também os conceitos de poder e autoridade, muito explorados nas bibliografias utilizadas.

\subsection{Conceitos}

Liderar, segundo James Hunter (2014, p.115), é a "habilidade de influenciar pessoas para que trabalhem com entusiasmo por objetivos identificados como voltados para o bem comum, com um caráter que inspire confiança e excelência"

Liderança, segundo Covey (2017, p. 23), "é comunicar o potencial e o valor dos outros com tanta clareza que eles se sintam inspirados a vê-los em si mesmos".

A versão online do dicionário Michaelis (s.d.) define como líder aquele "com capacidade de influenciar nas ideias e ações de outras pessoas". O Dicionário Aurélio (2016), em sua versão também online, define liderança como "Comando, direção, hegemonia (superioridade)".

A definição de "Chefe" é "Peça honrosa no terço superior do escudo; Funcionário ou empregado que dirige um serviço; Diretor; Cabeça, principal” (DICIONÁRIO AURÉLIO, 2016). A definição de "Gerente" é "pessoa que gere ou administra negócios" (DICIONÁRIO AURÉLIO, 2016).

\subsection{Chefe, Gerente e Líder}

Na vida empresarial, o gerente é um empregado de uma empresa, sendo este um intermediário entre o presidente e seus subordinados, sendo assim, podemos afirmar que este indivíduo é o chefe de uma determinada equipe, devendo mantê-la trabalhando de forma eficaz e eficiente durante todo o expediente. 
O líder, na maioria das vezes, encontra-se em um cargo de chefia e, apesar de muitas bibliografias colocarem liderança e gerência como competências antagônicas, as mesmas são complementares. Joseph C. Rost (apoud Geisler, 2013, p. 47) afirma que "qualquer conceito que engrandeça a liderança à custa da gerência é necessariamente falho".

Essa divergência é causada por paradigmas ultrapassados, que já não fazem mais sentidos na atualidade. O líder, devido ao fato de fazer uso da inteligência emocional, é muitas vezes confundido como um mero motivador, que não possui capacidades administrativas.

Já o paradigma do gestor é relacionado com a história da administração empresarial, quando a tecnologia ainda não era tão desenvolvida como atualmente e a maioria dos trabalhos realizados eram manuais, sem necessidade de capacidades intelectuais. Neste período, os gerentes apenas davam ordens aos subordinados sobre "o que" e "como" os mesmos deveriam realizar as atividades, tendo apenas a função de avaliar se as mesmas estavam sendo executadas de forma correta. Caso a avaliação fosse negativa, o chefe repreendia os trabalhadores responsáveis pela ação, normalmente de forma ríspida e desrespeitosa.

Essas atitudes causavam temor entre os funcionários e fazia com que os mesmos não se envolvessem com o trabalho. O resultado era a mediocridade do trabalho, greves, sabotagens no processo produtivo e até mesmo casos de violência (HUNTER, 2006).

O líder, diferente do gerente descrito acima, não faz uso do poder que lhe é concedido e sim da autoridade. A necessidade do desenvolvimento das capacidades de liderança nos chefes do século XXI se deve à evolução do mercado de trabalho, em que a demanda por mão de obra intelectual aumentou. Esses novos profissionais necessitam de condições ideais, de um ponto de vista psicológico, para exercerem suas funções.

Para compreender melhor o paradigma negativo do gerente e a definição de líder, torna-se necessário a distinção entre poder e autoridade.

\subsection{Poder}

Poder é definido como "a faculdade de forçar ou coagir alguém a fazer sua vontade, por causa de sua posição ou força, mesmo que a pessoa preferisse não fazer" (HUNTER, 2004, p. 29). Sendo este dado a alguém através de um cargo, posição social ou herança, podendo ser, também, tomado.

No passado, os gerentes eram coercivos, sendo respaldados pelo poder que sua posição hierárquica lhe concedia. No entanto, esta postura deteriorava as relações a longo prazo, causando baixo comprometimento e falta de confiança dos subordinados.

O resultado desse processo era uma postura defensiva e reativa dos funcionários, explicada pelo determinismo ambiental (COVEY, 2017), onde sempre existe um fator externo responsável pela falha pessoal, podendo ser atribuído à algum colega ou às condições de trabalho, a falta de recursos, dentre outros. Esta postura é o oposto do que se espera em um ambiente saldável e de alta produtividade.

\subsection{Autoridade}


Autoridade é definida como "a habilidade de levar as pessoas a fazerem de boa vontade o que você quer por causa de sua influência pessoal" (HUNTER, 2004, p. 29). Sendo esta uma habilidade, a mesma pode ser desenvolvida e aprimorada e, diferentemente do poder, deve ser conquistada, não podendo ser concedida ou confiscada.

Esta conquista deve ser feita através da dedicação ao liderado, demonstrando interesse pelo seu bemestar, pelo seu desenvolvimento, em fornecer as condições necessárias para que possa exercer seu trabalho com excelência, incentivando-o e motivando-o a buscar o seu melhor.

Os efeitos da autoridade são opostos ao do poder. Contrária à uma postura reativa, o funcionário que não trabalha para um chefe coercivo é proativo, ou seja, se responsabiliza pelos próprios atos, busca sempre a excelência e corrige seus erros ao invés de culpar a outros. O resultado é um ambiente saudável, onde existe interação entre as pessoas e a cooperação supera a concorrência.

\section{CARACTERÍSTICAS DOS LÍDERES}

Existem vários tipos de líderes e vários modelos de liderança. No entanto, algumas características são comuns aos bem-sucedidos.

Primeiramente, é importante destacar que, como afirma Daniel Goleman (2012), existem dois tipos de inteligência: a cognitiva, utilizada durante muitos anos como critério de excelência na vida profissional, sendo medida através dos testes de QI (Quociente de Inteligência), e a inteligência emocional (QE), termo em ascensão na atualidade. Sendo os dois tipos essenciais em um líder de sucesso.

\subsection{Inteligência Cognitiva}

A inteligência cognitiva está relacionada com as capacidades técnicas, sendo critério básico para que se tenha atingido o cargo de chefia. Pode-se destacar 3 competências básicas relacionados ao QI: Disciplina, Síntese e Criatividade (GARDNER, 2007).

Howard Gardner (2007), define uma mente disciplinada como aquela que possui um conhecimento profundo sobre um determinado assunto, o qual é aprimorado e atualizado constantemente, e um saber básico sobre o restante, tal como o de um neurologista sobre o sistema neurológico e seu entendimento sobre as demais competências da medicina.

A capacidade de síntese de um líder consiste em entender todo o conhecimento envolvido, o contexto das necessidades e os meios disponíveis e combiná-los de uma forma adequada que possa ser traduzido em palavras compreensíveis a todos os envolvidos ou em ações coesas com a demanda (GARDNER, 2007).

Devido ao mundo estar em constante evolução e essas mudanças estarem acontecendo de forma extremamente rápida nos últimos anos, problemas novos surgem a todo instante e as soluções do passado nem sempre funcionam com a mesma eficácia. Sendo assim, os líderes precisam sempre buscar saídas inovadoras, as quais podem ser desenvolvidas apenas por uma mente criativa, que tem a capacidade de propor soluções diferentes do habitual.

\subsection{Inteligência Emocional}


A inteligência emocional está relacionada com a capacidade de o indivíduo conhecer as próprias emoções, controlar as reações destas e, a partir disto, identificar o sentimento de outras pessoas e saber como interagir de forma adequada (GOLEMAN, 2012).

Este tipo de capacidade pode ser dividido em quatro competências: autoconhecimento, autocontrole, empatia e habilidade social. As duas primeiras são relacionadas à inteligência intrapessoal, voltada para si mesmo, e as duas últimas à interpessoal, "capacidade de compreender os outros" (GOLEMAN, 2012, p. 63)

A autoconsciência, como define Goleman (2012, p. 66), é a capacidade de "reconhecer um sentimento quando ele ocorre". As percepções sensoriais dos seres humanos produzem reações adversas, sendo que estas são instantâneas e impulsivas. O conhecimento de como reagimos à cada sensação é a chave para o próximo ponto da $\mathrm{QE}$, o autocontrole.

A autogestão consiste na capacidade de controlar as próprias reações, com base na consciência das mesmas. Reprimir o que se sente é impossível, mas o domínio das ações consiste em promover um equilíbrio entre a razão e a emoção, para que não se torne escravo da mesma. Segundo Goleman (2015, p.17), "pessoas que estão no controle de seus sentimentos e impulsos são capazes de criar um ambiente de confiança e equidade".

A partir disso, podemos passar a perceber os ânimos alheios, sendo esta a terceira competência da inteligência emocional, a empatia, sendo entendida como a capacidade do líder de tentar entender como o outro está se sentindo para que possa agir levando, ponderadamente, estes sentimentos em consideração (GOLEMAN, 2015).

Segundo Goleman (2015, p. 76):

Existem 3 tipos de empatia. A primeira é a cognitiva, em que você percebe como a outra pessoa pensa sobre o mundo, o que lhe permite expressar o que tem a dizer em termos que ela compreenderá. A segunda, emocional, em que você instintivamente ressoa com o sentimento da outra pessoa. A terceira, preocupação empática, em que você expressa como se importa com a pessoa ao ajudar naquilo que sente que ela precisa.

Por fim, a habilidade social, complementada pelas outras 3 competências da inteligência emocional, vai além da simples simpatia, sendo esta uma cordialidade com o propósito de persuadir os indivíduos a fazer o que o líder quer, sem a intenção de manipular os mesmos (GOLEMAN, 2015). Para tal efeito, o indivíduo deve conter suas reações para excitar a confiança alheia e demonstrar empatia ao se relacionar.

\subsection{Características de um Líder}

Como citado anteriormente, o bom líder desenvolve sua autoridade. Sendo assim, James Hunter (2004, p. 34) lista as características comuns às pessoas que possuem autoridade indiscutível:

Honestidade e confiabilidade; bom exemplo; cuidado; compromisso; bom ouvinte; conquista a confiança das pessoas; tratava as pessoas com respeito; encorajava as pessoas; atitude positiva e entusiástica; 
gostava das pessoas.

A honestidade é definida por Hunter (2004, p. 94) como "ser livre de engano", ou seja, uma pessoa honesta não engana, não mente e não manipula, devendo esta característica fazer parte dos princípios de um líder, assim como a capacidade de honrar os compromissos firmados. Segundo Hunter (2004), o não cumprimento destes envia uma mensagem negativa aos envolvidos, tal como o descaso e a ideia de que não são importantes. Um chefe é exemplo para seus liderados, sendo assim, deve possuir valores bem definidos.

Um bom gestor cuida de seus funcionários, ouvindo-os com atenção e empatia, tentando suprir as necessidades legítimas dos mesmos, para que tenham condições para desempenhar seu trabalho com excelência. Além disso, encoraja as pessoas para que se desenvolvam e arrisquem, fornecendo apoio e tratando-as com respeito, caso ocorra um resultado negativo. Estas atitudes fortalecem a confiança.

O respeito é uma característica fundamental na atmosfera de trabalho. Hunter (2004) afirma que respeitar as pessoas é tratá-las como gostaria de ser tratado, ou seja, sendo humilde, honesto, gentil e paciente. A arrogância, a falta de educação e a intolerância deterioram as relações e os ambientes profissionais.

Por fim, um bom líder é um bom ouvinte, sendo esta uma forma de mostrar que os liderados são importantes e devendo ouvi-los de uma forma empática, tentando entendê-los. Esta dedicação de tempo aos funcionários permite ao chefe entender às reais necessidades, as quais devem ser levadas em consideração para dá-los condições para exercer um bom trabalho e mantê-los motivados.

\section{TIPOS DE PERSONALIDADES}

Para entendermos melhor os tipos de gestores, torna-se necessário uma breve exposição sobre algumas personalidades. Isto também será importante para o líder na construção dos relacionamentos, na motivação individual, no feedback e na manutenção do ambiente.

Neste tópico serão abordados seis tipos de personalidade, os quais são citados por Jill Geisler (2013): extrovertidos, introvertidos, "durões”, sensíveis, planejadores e impulsivos.

Os extrovertidos, perfil comum nos líderes afiliativos, são comunicativos, necessitando estar em contato constante com outras pessoas. O silêncio e a solidão os incomodam e afetam sua produtividade. Em uma reunião, são caracterizadas por não serem bons ouvintes, costumam interromper enquanto outros estão falando, além de não pensarem muito para falar. Estas características, caso não administradas adequadamente, podem dispersar a atenção durante as reuniões e torná-las mais demoradas do que o necessário. No entanto esses indivíduos são sociáveis e costumam descontrair o ambiente de trabalho

O oposto à última personalidade são os introvertidos, perfil comum nos líderes Visionários, Coach e Democrático. Estes preferem ambientes silenciosos e solitários, são bons ouvintes e gostam de pensar mais sobre um assunto antes de expressar sua opinião. Em reuniões, costumam ser mais diretos e objetivos, se incomodando com a desorganização do encontro, além de preferirem se preparar previamente para o mesmo.

Os “durões”, perfil comum aos líderes Coercitivos, são caracterizados por não levarem em consideração 
as opiniões de outras pessoas. Costumam fazer poucos elogios, fazendo-os apenas para quem ultrapassa as metas estabelecidas, fazem críticas de forma direta, sem pedir esclarecimentos ao liderado. Este tipo de personalidade costuma ser péssimo para o ambiente de trabalho, criando inseguranças e deteriorando as relações.

O oposto dos "durões" são os "sensíveis", perfil comum em líderes Afiliativos e Coaches. Os chefes com esta característica sempre levam em consideração os sentimentos dos liderados. Veem o elogio como uma forma de valorizar o indivíduo, dando-o sempre que um bom trabalho é realizado. Para dar feedback negativo, costumam primeiro ouvir o funcionário para tentar entender melhor o ocorrido, o que atenua o efeito inconveniente da crítica.

Os planejadores, perfil comum aos líderes Marcadores de Ritmo, são seres organizados, que gostam de trabalhar atendendo rigorosamente os prazos estabelecidos, além de fazerem uma separação entre trabalho e diversão, tornando-se facilmente chefes controladores.

Os impulsivos, por outro lado, são normalmente desorganizados, deixando para realizar as atividades mais próximas à data de entrega, além de se divertirem enquanto trabalham. Esta última característica incentiva a criatividade, o que pode ser desejável em algumas ocasiões.

\section{TIPOS DE LÍDERES}

Segundo Daniel Goleman (2015), existem 6 tipos de líderes: Afiliativo, Coach, Coercivo, Democrático, Marcadores de Ritmo e Visionário. No entanto, os bons líderes não apresentam apenas um destes modelos de liderança. Segundo o próprio Goleman (2015, p. 44):

Líderes que dominaram quatro ou mais - especialmente os estilos visionário, democrático, afiliativo e coaching - conseguem o melhor clima e desempenho empresarial. E os líderes mais eficazes alternam flexivelmente entre os estilos de liderança na medida do necessário.

\subsection{Líder Afiliativo}

Neste modelo, os liderados são colocados em primeiro lugar, seus sentimentos ficam acima das tarefas. Profissionais com este perfil desenvolvem vínculos fortes com sua equipe, o que favorece a comunicação e o compartilhamento de ideias (GOLEMAN, 2015).

Os ambientes criados por estes chefes são mais integrados e harmônicos, imperando a cooperação e não a competição. O resultado disso são funcionários mais felizes e fiéis aos times. Além disso, o feedback é uma ferramenta aplicada constantemente, principalmente o positivo, que tem o poder de motivar (GOLEMAN, 2015).

Apesar de todas estas boas características da liderança afiliativa, os líderes com este perfil devem tomar cuidado para não perderem o controle dos liderados. Um dos resultados disso são os chamados "microgerenciamento" (GOLEMAN, 2015) e "subgerenciamento" (TULGAN, 2009), ocorrendo quando o gerente, insatisfeito com o trabalho de um subordinado, mas com medo de fornecer-lhe um feedback negativo, acaba se sobrecarregando com as atividades que deveriam ser realizados pelo mesmo. 
Não dar orientação, segundo Geisler (2013), resulta em mediocridade do trabalho realizado e a sobrecarga dos bons liderados, além da perda de respeito com os demais e a degeneração do ambiente de trabalho.

\subsection{Líder Coach}

O líder Coach é conhecido por desenvolver seus funcionários. Primeiramente, o mesmo auxilia seus liderados a identificarem suas forças e fraquezas e os incentiva e ajuda a melhorarem suas habilidades a longo prazo. Além disso, o mesmo mantém contato constante com sua equipe para que possa sempre identificar as necessidades e fornecer feedback sempre conveniente.

Os chefes com este perfil delegam funções desafiadoras aos seus subordinados com a intensão de treinálos e, diferentemente dos gerentes coercivos, não diz como quer que o trabalho seja desenvolvido e sim o que espera no final, usando esta oportunidade para auxiliá-los a encontrarem o método mais adequado.

Quando o liderado não atinge o objetivo desejado, o Coach auxilia-o a identificar as causas do erro e o que pode ser feito para a sua correção, além disso, fornece feedback constante para que tenha conhecimento do próprio desempenho.

Este tipo de liderança é pouco aplicado no mundo dos negócios, devido a requerer muito tempo para treinar os funcionários. No entanto, a longo prazo, este treinamento resulta na economia do mesmo, deixando a equipe mais apta a realizar as atividades delegadas.

\subsection{Líder Coercivo}

O líder Coercivo, ou autoritário, é caracterizado por fazer uso do poder e não da autoridade, sendo considerado por Goleman (2015) o modelo menos eficaz de liderança. Os profissionais com esse perfil são normalmente arrogantes e rígidos, não assumem seus erros, não pedem ajuda a profissionais mais capacitados quando precisam e cobram que suas ordens sejam cumpridas sem questionamento.

A tomada de decisões destes chefes é feita individualmente, sem levar em consideração, ou mesmo pedir a opinião dos funcionários, o que interfere na qualidade e na adesão a mesma, visto que a diversidade e a deliberação são essenciais neste processo.

Os Coercivos são também conhecidos pela habitual falta de paciência ao lidarem com erros dos liderados. Além de não fornecerem orientação ou desenvolverem seus subordinados, costumam dar feedback de forma ríspida, verbalmente agressiva e não construtiva, apenas humilhando o indivíduo.

\subsection{Líder Democrático}

O líder Democrático é caracterizado por convocar uma reunião sempre que precisar tomar uma decisão importante, sendo realizada com todos que serão afetados pelas decisões a ser tomada, para que discutam o problema e cheguem a um consenso.

Daniel Goleman (2015, p. 40) descreve as vantagens deste modelo:

Ao dedicar tempo para ouvir as ideias e obter a adesão das pessoas, um líder desenvolve confiança, 
respeito e compromisso. Ao deixar que os próprios trabalhadores tenham influência nas decisões que afetam suas metas e como realizam o trabalho, o líder democrático aumenta a flexibilidade e responsabilidade. E ao ouvir as preocupações dos funcionários, o líder democrático aprende como manter a moral elevado. Finalmente, por terem influência na definição de suas metas e dos padrões para avaliar o sucesso, as pessoas no sistema democrático tendem a ser bem realistas sobre o que pode ou não ser alcançado.

Por outro lado, este estilo de liderança pode ser marcado por excesso de reuniões, as quais podem ser longas e, muitas das vezes, por não serem objetivas e não atingirem os resultados esperados, costumando ser acaloradas.

\subsection{Líder Marcador de Ritmo}

Este é o estilo de liderança adequado apenas a equipes homogêneas, nas quais todos são igualmente competentes e capacitados, necessitando de pouca ou nenhuma instrução e onde o simples fato de se conseguir atender às demandas do chefe de forma satisfatória serve como motivação (GOLEMAN, 2015).

Os líderes com este perfil estabelecem elevados padrões de excelência, colocando metas ambiciosas e prazos estreitos, sendo o próprio um exemplo do desempenho esperado de sua equipe. Além de serem extremamente exigentes, acompanham os trabalhos de perto, para apontar os erros e garantir que sejam corrigidos rapidamente.

Este tipo de chefia é péssimo para um ambiente profissional com equipes heterogêneas, onde os funcionários se sentem muito pressionados pelas exigências, além da insegurança de terem que descobrir sozinhos o que o líder espera de cada atividade. Os profissionais destas equipes apresentam baixo nível de confiança para desempenharem suas tarefas, devendo-se à falta de orientação e feedback e a possibilidade de serem demitidos subitamente por não atenderem às expectativas.

\subsection{Líder Visionário}

O líder Visionário, segundo Goleman (2015, p. 33), "motiva as pessoas ao deixar claro como o trabalho delas se enquadra numa visão maior para a organização. Pessoas que trabalham para tais líderes entende que o que fazem importa e porquê".

Este estilo de liderança, segundo Goleman (2015), é o mais eficiente. Isto se deve ao fato do chefe ser flexível, sendo que o mesmo estabelece a meta e a traduz de uma forma inspiradora, dando-lhe um senso de importância, não determina a metodologia a ser usada, deixando-a aberta para que os liderados encontrem as mais adequadas às necessidades.

\section{TREINAMENTO}

Segundo James Hunter (2006), o líder é o responsável pelo sucesso e fracasso de seus liderados. Sendo assim, o mesmo tem a função de preparar seus funcionários para executarem com excelência as próprias obrigações, fornecendo treinamento adequado.

Esta obrigação do chefe também é importante quando pretende-se realizar uma promoção dentro da 
própria equipe. Deve-se então escolher os candidatos que possuem o perfil mais adequado ao cargo e prepará-los. Caso o escolhido não esteja apto, o efeito para o próprio e para a empresa pode ser devastador, perdendo-se um bom profissional em um posto e o colocando-o para uma responsabilidade superior à sua capacidade, podendo até destruir a carreira.

Peter Drucker (2016) chama atenção para um erro comum quando pretende-se promover um indivíduo tentando adaptar o cargo ao mesmo. O autor supracitado ressalta que a função é estruturada pela atividade a ser desempenhada e não pela personalidade de quem irá desempenhá-la, sendo que, uma mudança desta natureza na empresa geraria uma série de outras alterações, devendo-se à interdependência dos postos de uma organização.

Os treinamentos, de uma forma geral, são compostos por cinco fases: encontrar as pessoas mais adequadas à função e saber sua vontade em desempenhá-la, ensinar os fundamentos, delegar atividades, dar orientação para a correção dos erros e colocar o aprendizado em prática.

O primeiro passo consiste em identificar os profissionais que melhor atendem as exigências do novo posto e, depois de explicar o novo desafio para os mesmos, saber se estão dispostos a assumir as novas responsabilidades. A etapa seguinte se resume em apresentar as tarefas a serem realizadas e estabelecer os padrões de desempenho.

O terceiro estágio é delegar as atividades. Segundo Stephen Covey (2017), existem dois modos de se fazer isso: dando ordens (delegação restrita) ou fornecendo orientação (delegação administrativa). Estas duas possibilidades obtêm resultados opostos. A primeira delas consiste em dizer "o que" realizar e "como", fazendo com que o liderado fique preocupado com os métodos usados, tentando decorar a sequência necessária para realizar o trabalho. No segundo modelo, o líder estabelece os resultados esperados e deixa que o funcionário busque as práticas que mais se adequam ao seu modo de trabalhar, fornecendo apenas dicas para que o mesmo obtenha o resultado almejado.

A quarta fase consiste em fornecer orientação para a correção das falhas, visando a otimização do processo. Enquanto o mesmo começa a trabalhar em sua nova missão, utilizam-se os erros cometidos como oportunidades para ensiná-lo. Para fazê-lo de forma adequada, primeiramente deve-se identificar a defasagem, comparando o resultado apresentado com o padrão esperado.

Posteriormente, os envolvidos se reúnem para identificar e discutir as possíveis causas. Neste momento é importante que o líder evite dar sugestões sobre as possibilidades, fazendo que o liderado as identifique sozinho. Em seguida, discutem-se e criam planos de ação para eliminarem os defeitos. O último passo do treinamento consiste em colocar em prática e exercitar o que foi aprendido, definido por James Hunter (2016) como "fricção".

\section{FEEDBACK}

O feedback desempenha uma função muito importante em uma organização, auxiliando, principalmente, na formação do funcionário e no aprimoramento de seus conhecimentos. James Hunter (2014) ressalta que o líder tem a tarefa de desenvolver seu liderado, de forma que o mesmo seja mais capaz após ser admitido do que antes de sê-lo, fortalecendo a equipe, deixando a empresa mais competitiva, num cenário comercial e evitando o "microgerenciamento". Outra função importante desta ferramenta é a de motivar. 
O gerente deve estar atento às qualidades e as deficiências dos indivíduos. Sendo assim, o feedback se divide em duas categorias, o positivo e o negativo. $O$ primeiro tipo tem uma grande capacidade de motivar os receptores, sendo utilizado na forma de elogio. O efeito deste é uma sensação de importância, fazendo com que a pessoa que o recebeu se sinta necessário, o que o estimula a buscar a excelência.

A exaltação de uma tarefa bem realizada deve ser feita de forma sincera e específica, ou seja, deve-se fazêla direcionando-a a alguém e dizendo o que realmente foi feito de bom.

O segundo tipo, por mais que seja desagradável fazê-lo, é, muitas vezes, mais necessário que o primeiro. $\mathrm{O}$ feedback negativo tem a intenção de corrigir um comportamento ou um método de trabalho inadequado do funcionário, devendo ser realizado próximo ao ocorrido. Daniel Goleman (2012) chama a atenção para os prejuízos do adiamento desta obrigação do líder, causando, normalmente, um acúmulo de insatisfações acarretando em críticas com tom de arrogância e sarcasmo, o que cria um sentimento de tristeza e raiva no interlocutor, desmotivando-o ou causando uma discussão.

Para que o chefe possa fazer uso dessa ferramenta frequentemente, é necessário que o mesmo disponibilize um tempo para conversar com seus subordinados rotineiramente, estendendo esta conversa tanto aos bons quanto aos ruins. Esta ação é importante para que se estabeleça uma relação agradável entre gerente e gerenciado, servindo para o primeiro entender melhor como se comunicar, motivar ou fazer uma crítica ao segundo, de forma com que o efeito desta não seja tão incômodo.

No instante em que o líder for dar um feedback negativo, é importante que tente entender os motivos do liderado, ouvindo atenta e empaticamente para que haja uma "ligação" entre os envolvidos. Após o esclarecimento, o chefe deve falar de forma respeitosa, clara e objetiva, sem fazer rodeios, para que possa passar a mensagem pretendida e impulsionar a mudança requerida.

O responsável pela abordagem deve prestar atenção em como realizará a mesma, tomando cuidado com as palavras usadas para iniciar a conversa, o tom de voz e a expressão corporal. Isso é necessário para confortar o interlocutor, obter-se o melhor efeito possível e não despertar reações negativas.

Daniel Goleman (2012) afirma que existem diversos tipos de emoção, tal como ira, tristeza, medo, felicidade, surpresa, nojo e vergonha, e que o ser humano possui uma reação instantânea, armazenada em seu cérebro, para cada uma delas. Uma abordagem que seja identificada como agressiva pode causar uma interpretação errada do que foi dito.

Daniel Goleman (2015, p. 99) destaca que a forma de apresentação é mais importante do que a mensagem transmitida:

Em um estudo recente, nossa colega Marie Dasborough observou dois grupos: um recebeu um feedback de desempenho negativo seguido por sinais emocionais positivos - a saber, movimentos de cabeça e sorrisos. O outro recebeu um feedback positivo que foi transmitido criticamente, com caras fechadas e olhos semicerrados. Em entrevistas subsequentes conduzidas para comparar os estados emocionais dos dois grupos, as pessoas que haviam recebido feedback positivo acompanhado de sinais emocionais negativos relataram sentimentos piores sobre seu desempenho do que os participantes que receberam feedback negativo de forma amigável. 
Existem vários erros que podem ser cometidos ao dar um feedback, no entanto, o que possui o pior efeito e o que mais deve ser evitado é a crítica individual em público. Essa ação causa constrangimento não apenas no alvo, mas também em todos que estão presentes, resultando em um sentimento de vergonha generalizado e um sentimento de repulsa em relação ao chefe.

\section{MOTIVAÇÃO}

Daniel Goleman (2012) alega que as emoções exercem uma função importante na capacidade do ser humano de produzir. Esta afirmação explica a necessidade de se motivar os liderados, transmitindo sentimentos de esperança e otimismo, os quais elevam a moral, inspiram a exercer melhor a função, a enfrentar os desafios com determinação e a encarar os erros como oportunidade de aprendizado.

Os chefes que não motivam seus subordinados de forma adequada estão sujeitos a obterem como resultado equipes apáticas, que adotam posturas defensivas quando obtêm resultados negativos, escondendo-se atrás de explicações ao invés de tentar corrigir os erros.

Mário Sergio Cortella (2016) afirma que a motivação ocorre de dentro para fora, partindo do indivíduo a ser motivado. Sendo assim, o gerente deve identificar quais são os fatores intrínsecos individuais e aprender como excitá-los, como através de um elogio, de conversas em que demonstre empatia ou mesmo fornecendo condições adequadas para que desempenhem um bom trabalho.

As condições supracitadas são as necessidades reais dos funcionários e não meras vontades. Segundo James Hunter (2014, p. 68), "A vontade é um anseio que não leva em consideração as consequências" e a "necessidade é um requisito físico ou psicológico legítimo para o bem-estar de um ser humano" (HUNTER, 2014, P. 69).

Como dito anteriormente, as emoções são fatores preponderantes no desempenho humano e, segundo Daniel Goleman (2015), muitas destas são contagiantes, destacando-se as positivas como as com maior poder de contágio.

O líder é visto como a figura maior de uma equipe, sendo este, muita das vezes, tomado como exemplo dentro de uma organização. Sendo assim, chefes bem-humorados obtêm, segundo Daniel Goleman (2015), resultados mais positivos de seus liderados. O humor positivo fornece ao ambiente uma sensação de otimismo e esperança, resultando em proatividade, estimulando a criatividade, elevando as expectativas em relação as metas e a confiança em relação aos desempenhos individuais e coletivos.

O oposto também é verdadeiro. Apesar dos sentimentos negativos não serem tão contagiantes, gerentes pessimistas obtêm piores resultados de seus subordinados. Os indivíduos com estas características não são bons em reconhecer quando um trabalho é bem executado, sendo também mais críticos. A crítica, além de diminuir a moral do indivíduo, censura os funcionários criativos, deixando-os inseguros para proporem novas ideias, muitas vezes necessárias para empresa (GARDNER, 2007).

\subsection{Tipos de Motivação}

Jill Geisler (2013) afirma que existem dois tipos de motivação, a extrínseca e a intrínseca. A primeira deriva de fatores externos, tais como bonificações, salários, dentre outros, sendo facilmente observados 
em serviços comissionados, onde o ganho é proporcional à produção.

Este modelo era muito usado pelos gerentes num passado recente, transformando-o num sistema de troca, onde o funcionário expunha suas vontades e o chefe dizia o que o mesmo deveria fazer para que o pedido fosse concedido. No entanto, o efeito motivacional era mínimo, obtendo-se uma mera obediência às ordens e não a inspiração à produção. Além disso, não existia a fidelização do liderado para com a empresa e a ausência dos bônus causava insatisfação generalizada e baixa produtividade.

O outro tipo de motivação é a intrínseca, sendo definido por Jill Geisler (2013, p. 108) como "o motor interno que impele a cada um de nós". Este modelo está relacionado ao sentido que o líder coloca na atividade e ao valor dado a quem a desempenha, gerando uma sensação de satisfação ao realizá-la. Geisler (2013) afirma que existem quatro propulsores internos: Competência, Autonomia, Propósito e Crescimento.

O primeiro está relacionado com o que o indivíduo faz de melhor, ou seja, qual das funções desempenhadas que o deixa mais satisfeito ao terminá-la. O bom líder identificam-nas e as usa a seu favor, delegando-as ao liderado certo, conversando com sobre o que está sendo realizado e elogiando-o sempre que possível.

O segundo impelidor é a autonomia, ou seja, dando liberdade para o subordinado realizar suas atividades da maneira que se sente mais à vontade, o que são, normalmente, métodos criados pelos próprios, o que os deixam satisfeitos ao verem que seu esforço está rendendo os resultados almejados. Além disso, esta ação funciona como uma demonstração de confiança, o que fortalece o efeito desejado.

Para que o chefe conceda esta independência, o mesmo deve ter um conhecimento claro sobre as capacidades do funcionário, treinando-o, caso necessário, e fornecendo orientação sempre que algo fuja do esperado.

O propósito é um motivador interessante, sendo este muito usado pelos líderes visionários. Neste caso, o gerente inclui a atividade num contexto global, dando-a um sentido de importância.

Por fim, a motivação através do próprio desenvolvimento. O profissional que se sente bem com o que faz e é reconhecido por isso busca sempre aprimorar seus conhecimentos e sua capacidade. A excelência é uma motivadora natural, relacionada com a autorrealização, ou seja, a satisfação em buscar ser o melhor em sua função, devendo esta ambição ser valorizada e explorada pelo líder.

\section{AMBIENTE DE TRABALHO}

O líder deve, por fim, desenvolver um ambiente de trabalho harmônico, onde haja cooperação entre os membros da equipe e os conflitos sejam de baixa intensidade e frequência. O primeiro passo para tal tarefa é a criação de um bom relacionamento com seus liderados.

Para iniciar uma boa relação com um funcionário, precisa-se incitar um sentimento de confiança e de respeito recíproco. Isto tem início através de conversas entre os mesmos, sendo que, nesta parte é importante que o chefe seja um bom ouvinte, com a intenção de compreendê-lo e não pensando no que irá dizer a seguir (HUNTER, 2014). 
Após este primeiro contato, e com o liderado sentindo-se valorizado, o gerente deve acompanhar o trabalho realizado, dando feedback, positivo e negativo, sempre que conveniente, além de incentivar e promover a interação com os outros funcionários.

Um local de trabalho agradável deve ser livre de emoções negativas, tal como inveja, desconfiança, desonestidade, arrogância, dentre outros. Para tal efeito, o líder, sendo o exemplo maior de uma equipe, deve ser bem-humorado, evitando ser pessimista, prepotente ou desonesto, usando sempre um tom de voz ameno e calmo.

Daniel Goleman (2015) destaca que, em dias tensos, com altas exigências, uma reação exaltada do chefe causa um sentimento de medo nos subordinados, resultando em uma baixa na produtividade e na moral da equipe, o que deixaria o ambiente com um aspecto apático ou até mesmo de tensão.

Por outro lado, como destaca Jill Geisler (2013), uma reação calma, num dia conturbado, transmite uma sensação de tranquilidade, fomentando a esperança e o otimismo, elevando o ânimo e, consequentemente, a capacidade de se resolver os problemas.

O melhor caminho para a manutenção de um ambiente saudável é através da criação de uma comunidade, sendo esta definida por James Hunter (2014, p. 144) como:

[...] um ambiente em que as pessoas tenham aprendido a aceitar e a transcender suas diferenças, a resolver seus conflitos em vez de evitá-los, a assumir responsabilidades pelo grupo, a se comunicar de forma eficiente e a criar um lugar onde possam ser elas mesmas.

Para estabelecer tal sociedade é necessário a criação de uma cultura forte e positiva, a qual é descrita por James Hunter (2014, p. 143) como: "um conjunto de hábitos, atitudes e mentalidades profundamente arraigados que determinam o modo de nos comportarmos na organização".

O líder pode normatizar os comportamentos da equipe, devendo ter início nas pessoas mais influentes nas equipes, para que sirvam de exemplo, e evitando compilados de regras extensos e confusos.

Deve-se evitar a criação dos grupos fechados, comumente conhecidos como "panelinhas", visto que estes feudos são, normalmente, afastados do restante da equipe, costumam reter informações e não cooperar com os demais, criando um clima de competição interno, sendo prejudicial ao bom funcionamento do conjunto.

Os chefes devem desmanchar essas associações, tentando promover a interação conjunta, o que muitas vezes pode significar ajudar na resolução de conflitos e rixas entre funcionários. A melhor maneira de fazê-lo é incentivar os envolvidos a conversar e expor os motivos da desavença e, após isso, que tentem entrar em um acordo sobre o assunto para poderem interagir novamente.

O bom relacionamento entre os membros de uma comunidade é necessário devido a interdependência dentro da organização. Devido à integração dos processos, a execução de uma atividade, depende da realização de outras, normalmente, sequenciais, o que exige a cooperação de todos os envolvidos, sendo necessária a utilização do sistema Ganha/Ganha, descrito por Stephen Covey (2017). 
Nesta estrutura visa-se o benefício mútuo, onde as decisões devem ser equilibradas para beneficiar a todos, a interação e o auxílio aos companheiros produzem resultados favoráveis à equipe inteira, fazendose o uso de uma mentalidade onde o esforço do coletivo é superior ao das partes separadas.

Ainda existem outros modelos como o Perde/Ganha, Ganha/Perde e o Perde/Perde (COVEY, 2017). O primeiro deles é um caso de submissão, onde o indivíduo abre mão do resultado para beneficiar a outro. No entanto, este modelo resulta em uma frustração individual, deixando o funcionário apático e desmotivado.

O segundo, é caracterizado por uma relação de competição, ou seja, para que um ganhe, o outro deve perder. Este sistema favorece os autoritários e a utilização de poder, no entanto, pode gerar conflitos e levar até a brigas.

O terceiro é uma consequência do anterior, onde o conflito toma um cenário de guerra e o fato de não poder "ganhar" causa a sabotagem do "concorrente", de forma que ambos sejam prejudicados, sendo este o pior modelo possível, comprometendo o desempenho da organização e a harmonia do ambiente.

\section{CONCLUSÃO}

Diante do exposto, conclui-se que, devido às exigências do mercado atual, do avanço da tecnologia e da mudança da mão de obra de força física para a de esforço intelectual, a liderança exerce, a cada dia mais, grande influência nos resultados de uma empresa.

Além disso, as características necessárias para um gerente ter sucesso no século passado necessitam ser complementadas pela inteligência emocional, a qual influência na motivação e na produtividade de uma equipe, sendo também importante para uma melhor comunicação e integração do ambiente de trabalho.

Com as inovações tecnológicas e a demanda crescente por mão-de-obra "pensante", surgiu a necessidade de treinar os liderados para melhor desempenharem suas funções, para assegurar a qualidade e garantir os resultados positivos.

O feedback precisou evoluir de uma simples crítica e repreensão, comum nos líderes Coercivos e gerentes do passado, para orientações e elogios, elementos primordiais no desenvolvimento dos funcionários e na função de inspirá-los a executarem um bom trabalho.

O sistema de troca, muito usado no passado para mobilizar as equipes a atingirem as metas, foi substituído por novas formas de motivar, partindo da necessidade de trabalhar com os sentimentos e emoções do indivíduo, dando liberdade para focarem nas atividades que lhe dão mais satisfação e para utilizarem as técnicas de sua preferência, dando propósito às atividades e oportunidade para se desenvolverem.

Por fim, o bom líder deve estabelecer relacionamentos saudáveis com seus subordinados, o que facilita a obrigação de dar feedback negativo e permite o conhecimento dos valores necessários para se motivar cada funcionário. Além disso, esta relação é necessária para implantar o sistema "Ganha/Ganha”, o qual favorece a cooperação entre os membros da equipe e permite a criação e uma comunidade. 


\section{REFERÊNCIAS}

BERGAMINI; Cecília Whitaker. Liderança: A Administração do Sentido. 1994. Disponível em: <http://www.scielo.br/pdf/rae/v34n3/a09v34n3.pdf>. Acessado em 28 jun. 2017.

BIANCHI, Eliane Maria Pires Giavina; QUISHIDA, Alessandra; FORONI, Paula Gabriela. Atuação do Líder na Gestão Estratégica de Pessoas: Reflexões, Lacunas e Oportunidades. 2016. Disponível em: <http://www.scielo.br/pdf/rac/v21n1/1415-6555-rac-21-01-00041.pdf>. Acessado em 28 jun. 2017.

CORTELLA, Mario Sergio. Por que fazemos o que fazemos?: Aflições vitais sobre trabalho, carreira e realização. 21. ed. São Paulo: Planeta. 2016. 174 f. ISBN: 978-85-422-0741-5

COVEY, Stephen R.. Os 7 hábitos das pessoas altamente eficazes. 61. ed. Rio de Janeiro: FranklinCovey. 2017. 462 f. ISBN: 978-85-7684-062-6.

DIAS, Daiane Souza; PERCIUNCULA, Gabriela; MAFFIA, Juliana; ANTONIOLLI, Pedro Domingos. Perfil: Uma Pesquisa da Liderança na Gestão de Projetos Com Profissionais da Área. 2017. Disponível em: <http://www.spell.org.br/documentos/ver/45076/perfil--uma-pesquisa-da-lideranca-nagestao-de-projetos-com-profissionais-da-area>. Acessado em 28 jun. 2017.

DIAS, Maria Aparecida Muniz Jorge; BORGES, Renata Simôes Guimarães e. Estilos de Liderança e Desempenho de Equipes no Setor Público. 2015. Disponível em: <http://www.scielo.br/pdf/read/v21n1/1413-2311-read-21-01-00200.pdf>. Acessado em 28 jun. 2017.

DICIONÁRIO AURÉLIO. (24 Setembro de 2016). Liderança. Disponível em: <https://dicionariodoaurelio.com/lideranca>. Acessado em 19 ago. 2017.

DICIONÁRIO AURÉLIO. (24 Setembro de 2016). Chefe. Disponível em: <https://dicionariodoaurelio.com/chefe>. Acessado em 19 ago. 2017.

DICIONÁRIO AURÉLIO. (24 Setembro de 2016). Gerente. Disponível em: <https://dicionariodoaurelio.com/gerente>. Acessado em 19 ago. 2017.

DRUCKER, Peter F.. O gestor eficaz. Rio de Janeiro. 2016. 238 f. ISBN: 978-85-216-1112-7

FILHO, Milton Cordeiro Farias, MIRANDA, Shirle Meira. Práticas Inovadoras e Estilo de Liderança na Gestão Pública Municipal Paraense. 2016. Disponível em: <http://www.spell.org.br/documentos/ver /44797/praticas-inovadoras-e-estilo-de-lideranca-na-gestao-publica-municipal-paraense->. Acessado em 28 jun. 2017.

GARDNER, Howerd. Cinco mentes para o futuro. Porto Alegre: Artmed. 2007. 160 f. ISBN: 978-85-363-0925-5

GEISLER, Jill. Como se tornar um ótimo chefe: Aprenda a obter o melhor de sua equipe e criar um ambiente de trabalho positivo. 1. ed. Rio de Janeiro: Sextante. 2013. 240 f. ISBN: 978-85-7542-960-0 
GOLEMAN, Daniel. Liderança: a inteligência emocional na formação de um líder de sucesso. 1. ed. Rio de Janeiro: Objetiva. 2015. 144 f. ISBN: 978-85-390-0651-9.

GOLEMAN, Daniel. Inteligência emocional: A teoria revolucionária que redefine o que é ser inteligente. 2. ed. Rio de Janeiro: Objetiva. 2012. 384 f. ISBN: 978-85-7302-080-9.

HUNTER, James C.. O monge e o executivo: Uma história sobre a essência da liderança. 1. ed. Rio de Janeiro: Sextante. 2004. 144 f. ISBN: 85-7542-102-6

HUNTER, James C.. Como se tornar um líder servidor: Os princípios de liderança de o monge e o executivo. 1. ed. Rio de Janeiro: Sextante. 2006. 144 f. ISBN: 85-7542-210-3

HUNTER, James C.. De volta ao mosteiro: O monge e o executivo falam de liderança e trabalho em equipe. 1. ed. Rio de Janeiro: Sextante. 2014. 192 f. ISBN: 978-85-431-0127-9

MARTINS, Pablo Luiz; CUNHA, Juliana Alves da; FARIA, Luiza Monique Castro; FERREIRA, Hugo Lucindo; NETA, Maria do Carmo Santos. Motivação e Liderança como Estratégias na Gestão de Pessoas. 2014. Disponível em: <http://www.aedb.br/seget/arquivos/artigos14/20020428.pdf>. Acessado em 28 jun. 2017.

MICHAELIS. (s.d.) Líder. Disponível em: <http://michaelis.uol.com.br/busca?r=0\&f= 0\&t=0\&palavra=1\%C3\%ADder $>$. Acessado em 19 ago. 2017.

MUZZIO, Henrique. Indivíduo, Liderança e Cultura: Evidências de uma Gestão da Criatividade. 2016. Disponível em: <http://www.spell.org.br/documentos/ver/43681/individuo--lideranca-ecultura--evidencias-de-uma-gestao-da-criatividade>. Acessado em 28 jun. 2017.

POLICARPO, Renata Veloso Santos; BORGES, Renata Simôes Guimarães e. Mudança Organizacional: Os Efeitos dos Estilos de Liderança no Comportamento dos Trabalhadores. 2016. Disponívelem: <http://www.spell.org.br/documentos/ver/44672/mudanca-organizacional--os-efeitos-dosestilos-de-lideranca-no-comportamento-dos-trabalhadores->. Acessado em 28 jun. 2017.

RUFFATTO, Juliane; PAULI, Jandir; FERRÃO, Augusto Rafael. Influência do Estilo de Liderança na Motivação e Conflitos Interpessoais em Empresas Familiares. 2016. Disponível em: <http://www.spe ll.org.br/documentos/ver/44971/influencia-do-estilo-de-lideranca-na-motivacao-e-conflitos-interpessoaisem-empresas-familiares>. Acessado em 28 jun. 2017.

RUSSO, Rosária de Fátima Segger Macri; RUIZ, Jose Moreno; CUNHA, Rosana Paulo Da. Liderança e Influência nas Fases da Gestão de Projetos. 2005. Disponível em: $<$ http://www.scielo.br/scielo.php?script=sci_arttext\&pid=S0103-65132005000300007>. Acessado em 28 jun. 2017.

SANT'ANNA, Anderson de Souza; CAMPOS, Marly Sorel; LÓTFI, Samir. Liderança: O Que Pensam Executivos Brasileiros Sobre o Tema? 2012. Disponível em: <http://editorarevistas.mackenzie.br/index.php/RAM/article/view/2884/3891>. Acessado em 28 jun. 2017. 
TULGAN, Bruce. Não tenha medo de ser chefe: Como combater a epidemia de subgerenciamento e se tornar o líder de que sua equipe precisa. 1. ed. Rio de Janeiro: Sextante. 2009. 192 f. ISBN: 978-85-7542-511-4.

[1] Engenheiro Mecânico. Pós-Graduando em Engenharia da Qualidade. Graduado em Engenharia Mecânica

\section{PUBLIQUE SEU ARTIGO CIENTÍFICO EM:}

https://www.nucleodoconhecimento.com.br/enviar-artigo-cientifico-para-submissao 